\title{
Fibronectin fibrillogenesis regulates three-dimensional neovessel formation
}

\author{
Xiaoming Zhou, ${ }^{1,6}$ R. Grant Rowe, ${ }^{1,6}$ Nobuaki Hiraoka, ${ }^{1}$ Jerry P. George, ${ }^{2}$ Denis Wirtz, ${ }^{2}$ \\ Deane F. Mosher, ${ }^{3}$ Ismo Virtanen, ${ }^{4}$ Michael A. Chernousov, ${ }^{5}$ and Stephen J. Weiss ${ }^{1,7}$ \\ ${ }^{1}$ The Division of Molecular Medicine and Genetics, Department of Internal Medicine, The Life Sciences Institute, \\ University of Michigan, Ann Arbor, Michigan 48109, USA; ${ }^{2}$ Department of Chemical and Biomolecular Engineering and \\ Institute for NanoBioTechnology, Johns Hopkins University, Baltimore, Maryland 21218, USA; ${ }^{3}$ Department of Medicine, \\ University of Wisconsin-Madison, Madison, Wisconsin 53706, USA; ${ }^{4}$ Institute of Biomedicine/Anatomy, University of \\ Helsinki, FIN-00014 Finland; ${ }^{5}$ Weis Center for Research, Geisinger Clinic, Danville, Pennsylvania 17822, USA
}

\begin{abstract}
During vasculogenesis and angiogenesis, endothelial cell responses to growth factors are modulated by the compositional and mechanical properties of a surrounding three-dimensional (3D) extracellular matrix (ECM) that is dominated by either cross-linked fibrin or type I collagen. While 3D-embedded endothelial cells establish adhesive interactions with surrounding ligands to optimally respond to soluble or matrix-bound agonists, the manner in which a randomly ordered ECM with diverse physico-mechanical properties is remodeled to support blood vessel formation has remained undefined. Herein, we demonstrate that endothelial cells initiate neovascularization by unfolding soluble fibronectin (Fn) and depositing a pericellular network of fibrils that serve to support cytoskeletal organization, actomyosin-dependent tension, and the viscoelastic properties of the embedded cells in a 3D-specific fashion. These results advance a new model wherein Fn polymerization serves as a structural scaffolding that displays adhesive ligands on a mechanically ideal substratum for promoting neovessel development.
\end{abstract}

[Keywords: Actomyosin; angiogenesis; endothelial cells; extracellular matrix; fibronectin]

Supplemental material is available at http://www.genesdev.org.

Received December 14, 2007; revised version accepted March 10, 2008.

Under quiescent conditions, the endothelium of the patent vasculature exists as a two-dimensional (2D) monolayer that rests atop a self-organized basement membrane that serves to separate the cells from the underlying interstitial matrix (Jain 2003; Carmeliet 2005). During angiogenesis and vasculogenesis, this structural arrangement is disrupted as endothelial cells embed themselves within a three-dimensional (3D) extracellular matrix (ECM) dominated by either cross-linked networks of the clotting protein, fibrin, or the triple-helical matrix molecule, type I collagen (Jain 2003; Carmeliet 2005). Within this extrinsic matrix, endothelial cells are exposed to angiogenic growth factors that initiate the migratory, proliferative, and tubulogenic responses required for the development of the neovasculature (Jain 2003; Carmeliet 2005). Growth factors acting alone, however, are unable to trigger angiogenesis (Chen et al. 1997; Huang et al. 1998; Geiger et al. 2001; Ingber 2006). Endothelial cells must concurrently establish productive integrin-mediated adhesive interactions with matrixbound ligands and undergo shape changes critical to the

${ }^{6}$ These authors contributed equally to this work.

${ }^{7}$ Corresponding author.

E-MAIL SJWEISS@umich.edu; FAX (734) 764-1934.

Article is online at http://www.genesdev.org/cgi/doi/10.1101/gad.1643308. activation of actomyosin-dependent contractile responses, which serve to trigger the motogenic, proliferative, and morphogenic programs that underlie neovascularization (Chen et al. 1997; Huang et al. 1998; Geiger et al. 2001; Discher et al. 2005; Ingber 2006; Vogel and Sheetz 2006).

Using traditional, 2D culture systems, the responsiveness of adherent cell populations to soluble growth factors is modulated by the composition, density, and topology of adhesive ligands as well as the mechanical properties of the supporting matrix itself (McBeath et al. 2004; Discher et al. 2005; Engler et al. 2006; Vogel and Sheetz 2006). However, an increasing body of evidence indicates that standard 2D culture systems do not recapitulate accurately cell behavior displayed in the $3 \mathrm{D}$ in vivo setting (Walpita and Hay 2002; Hotary et al. 2003; Chun et al. 2006; Nelson and Bissell 2006; Yamada and Cukierman 2007). Indeed, when cells are cultured within the confines of $3 \mathrm{D}$ extracellular matrices in vitro, cellmatrix adhesive interactions are established that more closely approximate those observed in vivo and, in coincident fashion, the cell cytoskeleton reorganizes into patterns that mimic those exhibited by intact tissues (Walpita and Hay 2002; Hotary et al. 2003; Beningo et al. 2004; Debnath and Brugge 2005; Meshel et al. 2005; Chun et al. 2006; Yamada and Cukierman 2007). Despite 
the described contrasts between 2D and 3D cell behavior, the mechanisms by which proangiogenic endothelial cells remodel the surrounding 3D ECM to generate an adhesive platform that allows them to interpret the biochemical and mechanical inputs critical to neovessel formation remain undefined. Here, we demonstrate that the endothelial cell-dependent unfolding and pericellular polymerization of the soluble glycoprotein, fibronectin $(\mathrm{Fn})$, plays a required-and 3D-specific-role in triggering neovascularization. By constructing a pericellular scaffold of polymerized Fn fibrils, endothelial cells are able to assemble a functional cytoskeletal-actomyosin complex and modulate their intracellular viscoelastic properties to engage the mechanotransduction-sensitive programs that drive $3 \mathrm{D}$ neovessel formation.

\section{Results}

\section{Endothelial cell tubulogenesis in $3 D$}

When embedded in a 3D gel of cross-linked fibrin and stimulated with a cocktail of proangiogenic factors in serum-containing media, human endothelial cells as- sume a spheroid configuration during the first $8-12 \mathrm{~h}$ of culture (Fig. 1A). Consistent with reports that endothelial cell rounding is incompatible with proliferative activity (Folkman and Moscona 1978; Chen et al. 1997; Ingber 2006), no increase in cell number is detected until after a 48-h culture period, whereupon the embedded cells display a stretched phenotype (Fig. 1A,B). Endothelial cell number subsequently increases after the 2-d lag period, and a tubulogenic program is engaged that leads to the formation of an anastomosing network of patent neovessels by day 6 (Fig. 1B,C). Neovessel formation in vitro recapitulates the in vivo program that is dependent on both $\alpha_{5} \beta_{1}$, a Fn-specific integrin, as well as the Fn RGD domain contained within its primary cell-adhesion module (Supplemental Fig. 1; Kim et al. 2000; Francis et al. 2002; Hynes 2002; Takahashi et al. 2007). Furthermore, as observed in vivo (Clark et al. 1982; Risau and Lemmon 1988; Neri and Bicknell 2005), endothelial cell morphogenesis occurs in tandem with the assembly of a network of Fn fibrils that not only enmesh the stretched endothelial cells observed at $48 \mathrm{~h}$, but also ensheath the tubules formed at the end of the 6-d culture period (Fig. 1D).

\section{A}

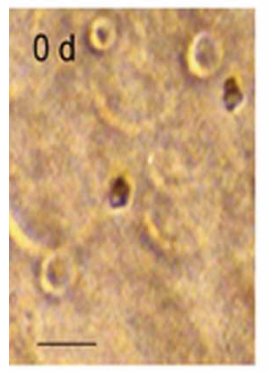

B
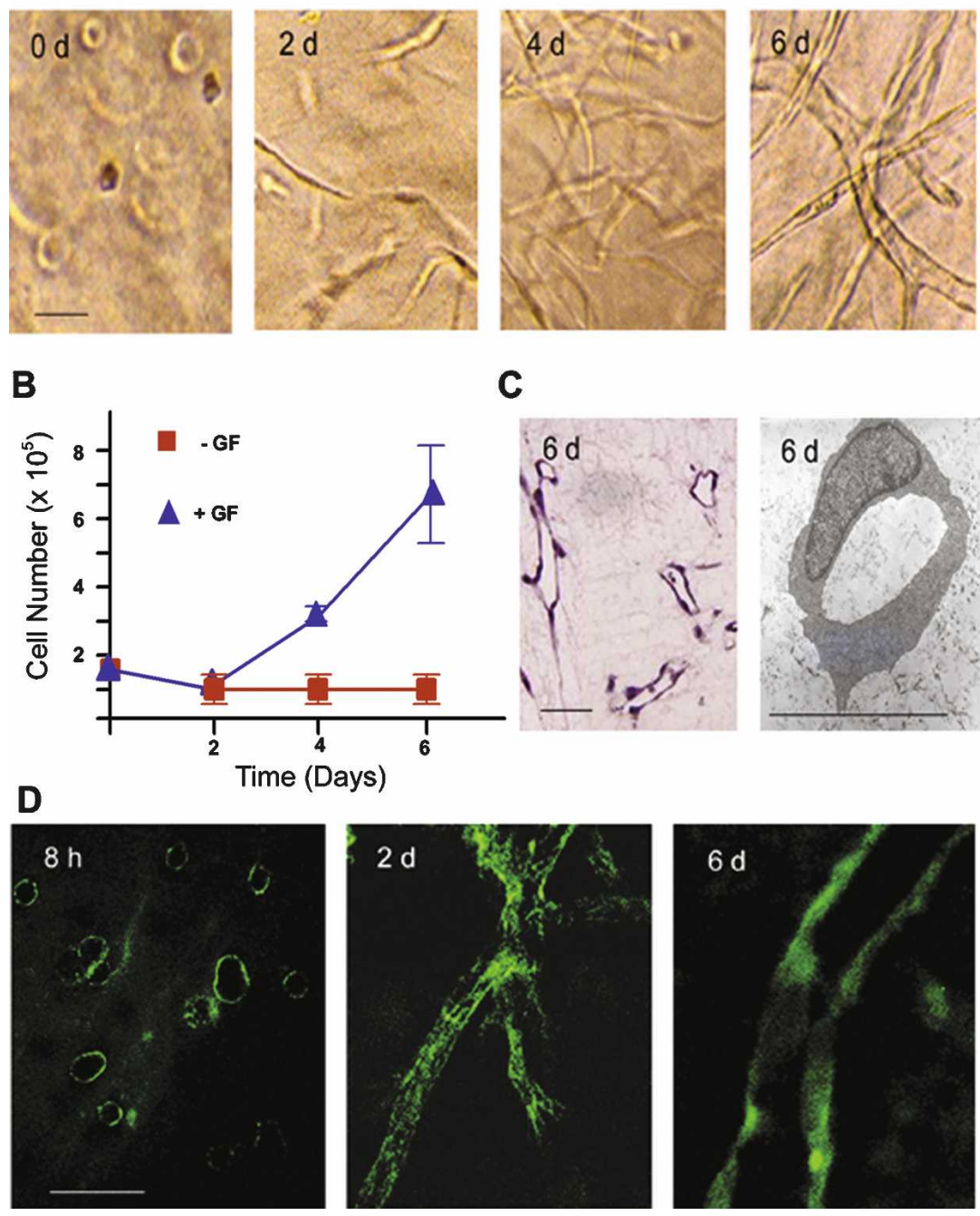

C

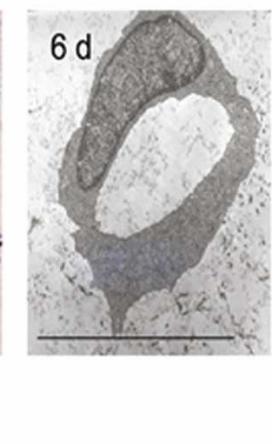

Figure 1. Endothelial cell tubulogenesis and Fn matrix assembly. (A) Endothelial cells $\left(1.5 \times 10^{5}\right)$ were embedded in a $3 \mathrm{D}$ fibrin gel in the presence of $20 \%$ human serum and a cocktail of VEGF, HGF, TGF $\alpha$, TGF $\beta_{1}$, and heparin. Phase contrast micrographs are shown following $0,2,4$, and $6 \mathrm{~d}$ in culture. $(B)$ Endothelial cell growth in the presence or absence of the provasculogenic cocktail was assessed by protease digestion of the $3 \mathrm{D}$ fibrin matrix followed by counting of cells. $(C)$ Following $6 \mathrm{~d}$ in culture, patent endothelial cell tubules are formed as assessed in H\&E-stained cross-sections or TEMs. ( $D)$ Confocal laser micrographs of pericellular assembly of FITC-labeled Fn matrix following $8 \mathrm{~h}, 2 \mathrm{~d}$, and $6 \mathrm{~d}$ of culture. Bar, $30 \mu \mathrm{m}$. 
The 3D-specific regulation of endothelial cell function by Fn fibrillogenesis

Under 2D culture conditions, cell shape changes critical to signal transduction, migration, and proliferation are dictated by the composition, organization, and rigidity of the surrounding ECM (Chen et al. 1997; Discher et al. 2005; Bershadsky et al. 2006; Vogel and Sheetz 2006; Cavalcanti-Adam et al. 2007). As changes in the morphology of 3D-embedded endothelial cells correlate with Fn matrix assembly, we first sought to characterize the functional role that the fibrillogenic process plays in the tubulogenic program. To block Fn matrix assembly without affecting the initial binding of soluble Fn binding to $\alpha_{5} \beta_{1}$, endothelial cells were incubated with (1) monoclonal antibodies directed against Fn domains embedded within, or near, the $\mathrm{Fn} \mathrm{III}_{1,2}$ modules that are critical for regulating Fn-Fn interactions (i.e., monoclonal antibody L8 or 9D2); (2) a 70-kDa N-terminal Fn fragment that interferes with the polymerization of intact Fn dimers by competing for matrix assembly sites on the endothelial cell surface; or (3) a 49mer peptide (termed the functional upstream domain, or FUD) derived from the Streptococcus pyogenes adhesion F1 protein, which binds directly to the N-terminal matrix assembly domain of Fn (Chernousov et al. 1991; Tomasini-Johansson et al. 2001, 2006; Mao and Schwarzbauer 2005). As exemplified by the addition of FUD (but not the control peptide Del29, wherein FUD residue 29 is deleted), the ability of fibrin-embedded endothelial cells to assemble a Fn matrix is blocked completely in the presence of inhibitors of Fn fibrillogenesis (Fig. 2A). In the absence of Fn fibrillogenesis-and despite the presence of a surrounding 3D fibrin matrix, serum, and exogenously provided proangiogenic growth factors-the endothelial cells are unable to undergo the expected shape change and retain a spherical morphology (Fig. 2A). Coincident with the block in Fn matrix deposition, the 3D migratory and proliferative responses of the embedded endothelial cells are blunted significantly and tubulogenesis is effectively terminated (Fig. 2B,C; Supplemental Fig. 2). Under these conditions, where $\mathrm{Fn} / \alpha_{5} \beta_{1}$ interactions are left intact, no increase in apoptosis (as assessed by TUNEL staining) is detected in the absence of Fn fibrillogenesis (data not shown). Furthermore, the ability of Fn matrix inhibitors to block neovessel formation is not restricted to the specific use of a fibrin gel suspension system. Similar, if not identical, results are obtained when neovessel formation is initiated with spheroids of endothelial cells embedded in 3D fibrin gels (Korff and Augustin 1998) or, alternatively, when type I collagen, the major ECM macromolecule found in mammalian tissues (Hotary et al. 2003; Chun et al. 2004, 2006), is used as the supporting matrix (Fig. 2D,E). Although Fn matrix assembly can regulate type I collagen deposition (Velling et al. 2002), neovessel formation is unaffected in the presence of the collagen synthesis inhibitor, cis-hydroxyproline (data not shown).

While the findings presented thus far support a required role for Fn fibrillogenesis in regulating endotheli- al cell behavior within the confines of a 3D ECM, endothelial cells are likewise able to assemble Fn matrices when cultured atop physiologic substrata (Fig. 2; Christopher et al. 1997; Bourdoulous et al. 1998). Consistent, however, with the fact that cell behavior can be affected differentially under 2D versus 3D culture conditions (Walpita and Hay 2002; Hotary et al. 2003; Debnath and Brugge 2005; Chun et al. 2006; Larsen et al. 2006; Yamada and Cukierman 2007), the inhibition of Fn matrix assembly during endothelial cell culture atop fibrin gels did not affect cell shape, migration, or proliferation (Fig. 2F-H).

Given the demonstrated requirement for Fn matrix assembly in $3 \mathrm{D}$ neovessel formation in vitro, a functional role for fibrillogenesis in tissue sites undergoing active angiogenesis in vivo was assessed. To this end, 3D composite gels of fibrin and type I collagen were placed atop the chorioallantoic membrane of live chicks and angiogenesis initiated by the application of a cocktail of growth factors in the presence of FUD or the Del29 peptide control. Under control conditions, angiogenic vessels infiltrated the ECM construct in tandem with the deposition of a dense network of Fn fibrils (Fig. 3A). In the presence of FUD, however, Fn matrix assembly is almost completely inhibited and neovessel formation is ablated (Fig. 3A,B). As monoclonal antibody L8 only recognizes unfolded Fn epitopes that are exposed during Fn fibrillogenesis (Chernousov et al. 1991; Zhong et al. 1998), Fn matrix assembly in the context of human tumor angiogenesis was also assessed. Immunostaining of a series of renal cell carcinomas (stages GI-III; $n=18$ ) and invasive ductal breast carcinomas $(n=8)$ demonstrates that vascular wall L8 immunoreactivity is dramatically increased in tissues undergoing active vasculo/ angiogenesis (Fig. 4). In both renal cell carcinoma and invasive ductal breast carcinoma specimens, all blood vessels and vascular channels are strongly L8-reactive with additional stromal staining seen in some cases of breast cancer (Fig. 4). In normal tissues, immunoreactivity for the L8 Fn epitope is observed infrequently as small streaks in $<10 \%$ of the vessels (Fig. 4).

\section{Fn fibrillogenesis and endothelial cell cytoskeletal organization}

Changes in cell geometry impact on the signaling cascades that control cell migration, proliferation, and morphogenesis (Chen et al. 1997; Tan et al. 2003; McBeath et al. 2004; Ingber 2006). In vivo, integrins and growth factors collaborate in the activation of mitogen-activated protein kinase (MAPK) pathways, which regulate the angiogenic response (Eliceiri et al. 1998; Geiger et al. 2001; Hoang et al. 2004; Ingber 2006). To determine the degree to which endothelial cell responses to growth factor and integrin-ligand signals are linked to Fn matrix assembly, the phosphorylation of the MAPKs ERK1, ERK2, JNK, and p38 were monitored in the absence or presence of fibrillogenesis inhibitors during the 48 -h period that precedes proliferative responses. In control cultures, sustained MAPK activation is maintained throughout the 48-h incubation period in a fashion that recapitulates the 
Zhou et al.

A

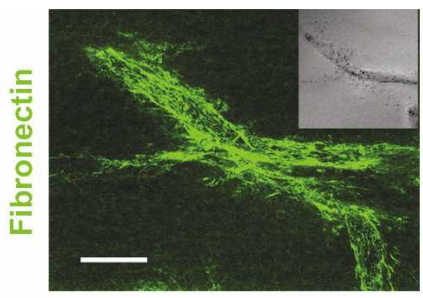

Del29

B

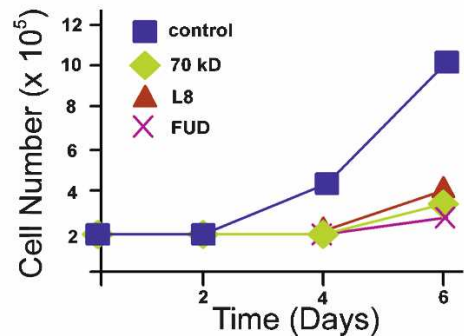

3-D Fibrin

D

$\lg G$

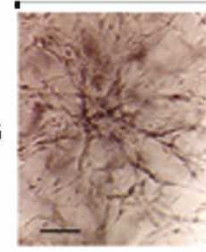

L8

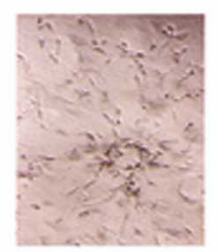

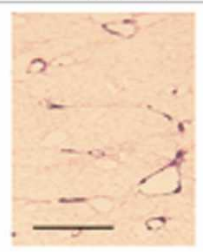

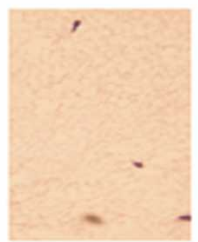

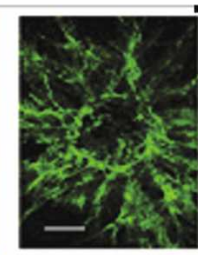

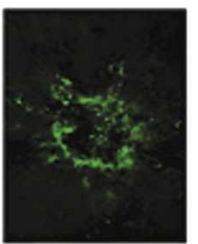

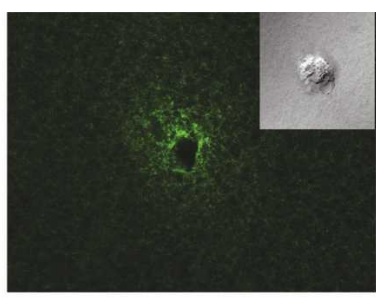

FUD

C

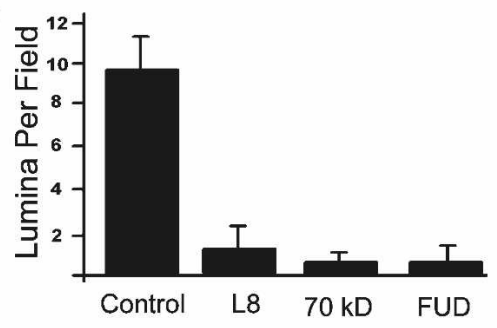

F

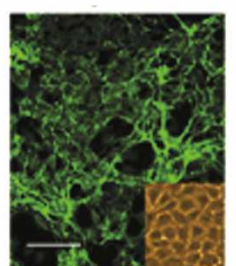

$\lg G$

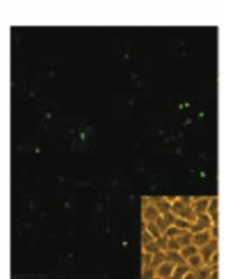

L8

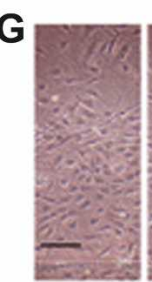

$\lg G$

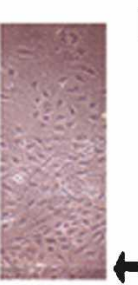

L8
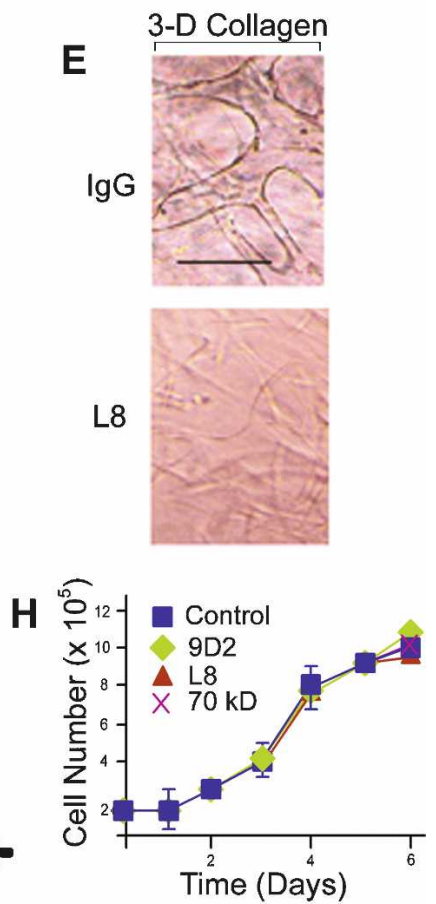

Figure 2. Fn matrix assembly regulates endothelial cell 3D morphogenesis. (A) Endothelial cells were suspended in 3D fibrin gels with FITC-labeled Fn in the absence or presence of the FUD peptide $(250 \mathrm{nM})$, with matrix assembly and cell morphology monitored by confocal laser microscopy. Bar, $20 \mu \mathrm{m}$. (B) Endothelial cells were cultured within 3D fibrin matrices for $6 \mathrm{~d}$ in the presence or absence of Fn matrix inhibitors. Cell number was quantified following gel digestion with collagenase. $(C)$ Endothelial cells were cultured in 3D fibrin gels under control conditions or in the presence of various Fn matrix assembly inhibitors for $6 \mathrm{~d}$, and tubulogenesis was assessed by sectioning and H\&E staining of the matrices followed by lumen quantification. $(D)$ Endothelial cells spheroids were embedded in gels of 3D fibrin and cultured for $6 \mathrm{~d}$ in the absence or presence of mAb L8 (100 $\mathrm{\mu g} / \mathrm{uL})$, and tubulogenesis was assessed by phase contrast microscopy (left panels in the top and bottom series) or light microscopy (H\&E-stained cross-sections in the middle column). (Right panels) The assembly of a FITC-labeled Fn matrix was monitored by confocal laser microscopy. Bar, $50 \mu \mathrm{m}$. (E) Endothelial cells were cultured within a matrix of type I collagen in the presence or absence of mAb L8 and tubulogenesis assessed at $6 \mathrm{~d}$ by phase contrast microscopy. Bar, $50 \mu \mathrm{m}$. $(F)$ Endothelial cells were cultured atop 3D fibrin gels for $6 \mathrm{~d}$ in the presence of L8 or control IgG. (Inset) Assembly of FITC-Fn into a fibrillar matrix was monitored by fluorescence microscopy, and cell morphology was assessed by phase contrast microscopy. $(G)$ Endothelial cell $2 \mathrm{D}$ migration was assessed atop a fibrin-coated substratum in the presence of IgG or L8 (arrowhead marks the edge of the monolayer at the start of the 2-d culture period). $(H)$ Endothelial cell growth was monitored during a 6 - $\mathrm{d}$ culture period in the presence of $\mathrm{mAb} \mathrm{L8}, \mathrm{mAb} 9 \mathrm{D} 2$, or the 70-kDa Fn fragment relative to an IgG control. Bar, $100 \mu \mathrm{m}$.

in vivo setting (Fig. 5A; Eliceiri et al. 1998; Corson et al. 2003). However, independent of the marked changes in endothelial cell morphology and cytoskeletal organiza- tion associated with the inhibition of Fn fibrillogenesis, phosphorylation patterns of ERK1/2, JNK, and p38 are largely unaffected (Fig. 5A). 


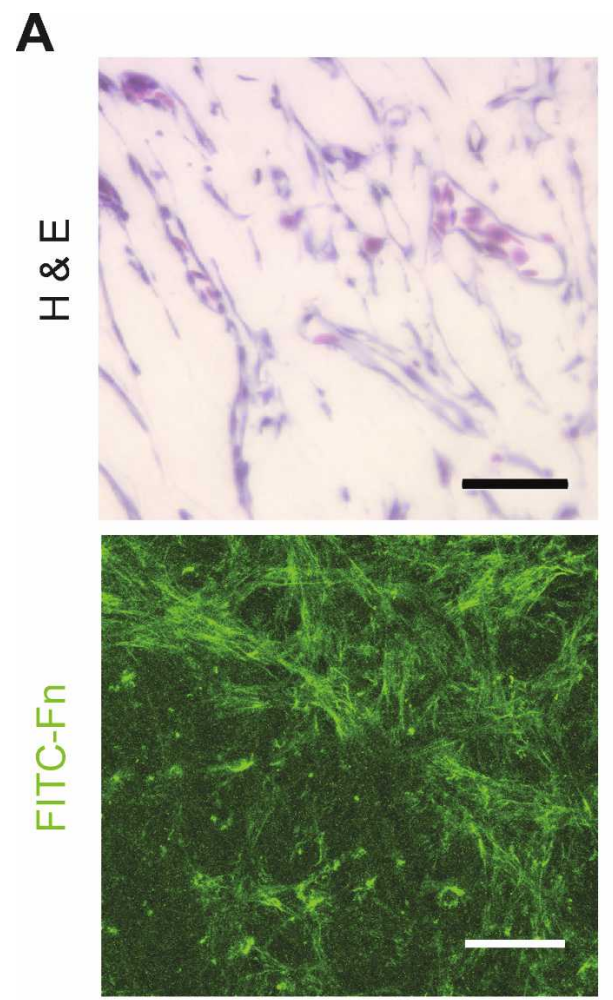

Del29
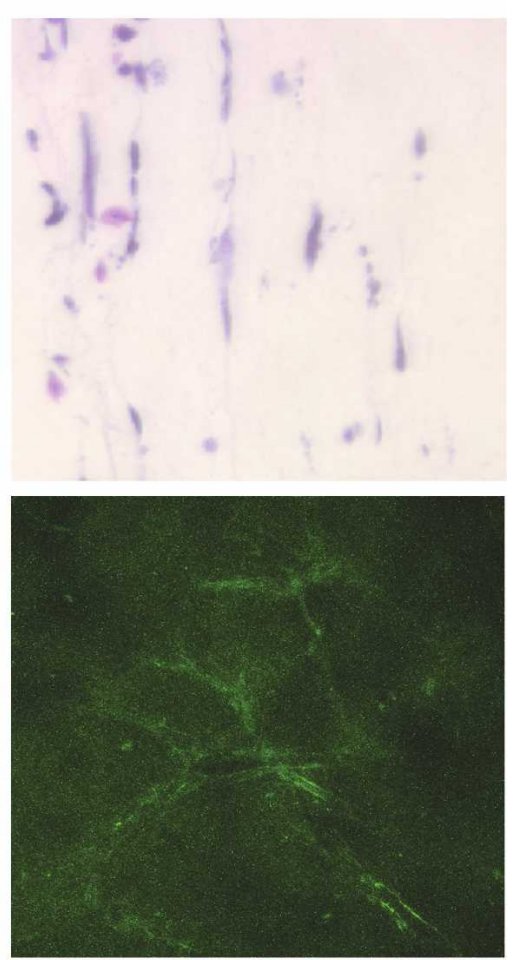

FUD
B

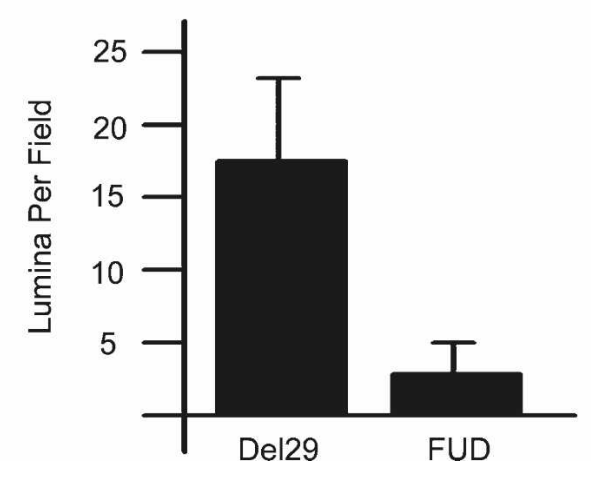

Figure 3. Fn matrix assembly is required for angiogenesis in vivo. (A) Type I collagen/ fibrin composite gels polymerized in perforated transwell chambers were prepared. A Matrigel reservoir containing $200 \mathrm{ng}$ of VEGF and 100 ng of HGF with either the Del29 control peptide or the FUD peptide was placed atop the matrix. (Top panels) The apparatus was placed atop the dropped CAM, and angiogenesis was allowed to proceed. After $3 \mathrm{~d}$, the gels were harvested and vascular ingrowth was monitored by light microscopy following $\mathrm{H} \& \mathrm{E}$ staining (bar, 40 $\mu \mathrm{m})$. (Bottom panels) In some experiments, FITC-Fn was supplemented in the matrices during the culture period, and Fn fibrillogenesis within the gels was monitored by confocal laser microscopy (bar, $50 \mu \mathrm{m})$. (B) After sectioning, lumina per $40 \times$ field were counted.
Despite the comparable initiation of signal transduction cascades in endothelial cells competent or incompetent for Fn matrix assembly, cell responses to integrin and growth factor-mediated signals are also dictated by the organization of actin cytoskeletal architecture /Chen et al. 1997; Huang et al. 1998; Bershadsky et al. 2006; Ingber 2006). In tandem with the ability of growth factorstimulated endothelial cells to adopt an elongated phenotype in $3 \mathrm{D}$ culture, a reticulated pattern of well-organized stress fibers is resolved by F-actin phalloidin staining when cells are cultured in the presence of the Del29 control peptide (Fig. 5B). In 3D culture, stress fibers terminate at specialized $\beta_{1}$ integrin- and vinculin-rich sites of cell-matrix interactions, termed 3D adhesions (Geiger et al. 2001; Larsen et al. 2006). As such, endothelial cells transduced with a GFP-tagged vinculin expression vector or alternatively immunostained with an activated $\beta_{1}$ integrin-specific monoclonal antibody target both vinculin as well as activated $\beta_{1}$ integrins into stitch-like structures at the endothelial cell periphery (Fig. 5C). In the absence of Fn fibrillogenesis, however, stress fiber formation is suppressed completely and actin staining is confined to the cortical envelope in a punctate network (Fig. 5B). Furthermore, specific interactions between either activated $\beta_{1}$ integrins or vinculin and F-actin networks can no longer be discerned (Fig. 5C). Endothelial cells alternatively cultured atop fibrin matrices in a $2 \mathrm{D}$ configuration assemble a well-organized stress fiber-focal adhesion network whose organization is unaffected by inhibitors of Fn fibrillogenesis (Fig. 5D).

\section{Fn matrix assembly induces myosin-dependent tractional forces}

Adhesive interactions between cells and their surrounding matrix allow for the generation of tractional forces 
Zhou et al.

A
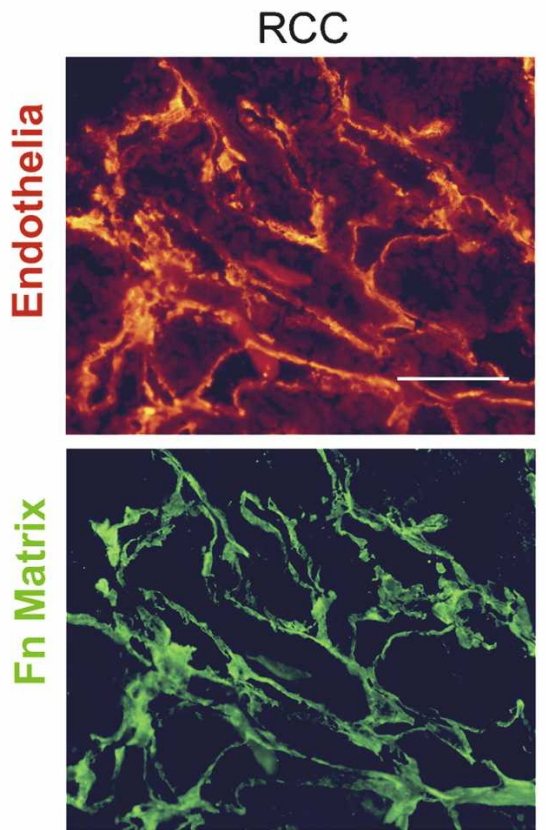

B
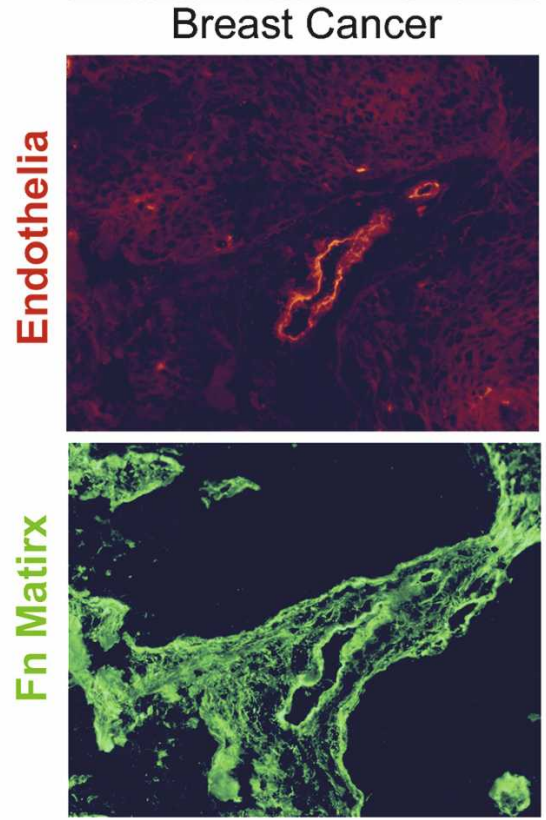

Normal Kidney
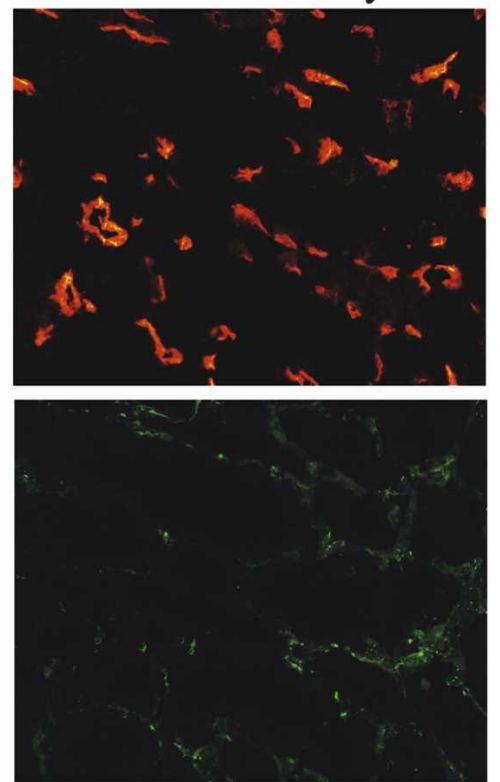

Normal Breast
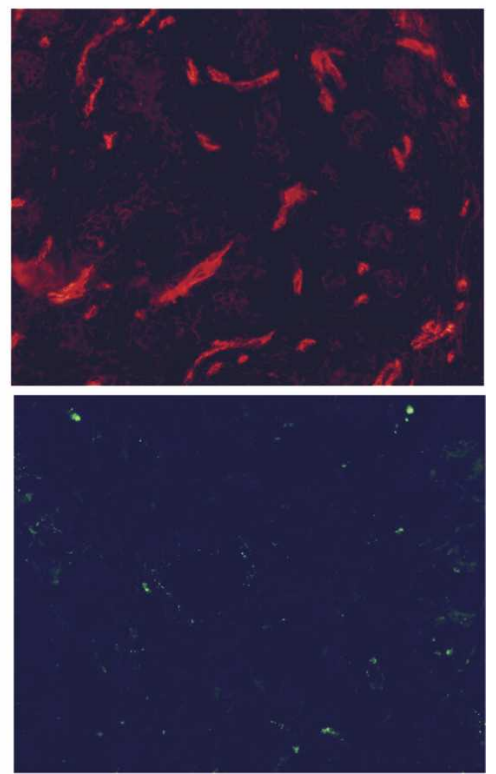

Figure 4. Fn matrix assembly is restricted to human neovessels in vivo. (A) Renal cell carcinoma (left panels) or normal kidney (right panels; $n=8$ ) were stained for UEA-1 (top panels, red) or with mAb L8 (bottom panels, green). (B) Breast carcinoma (left panels) was stained for UEA-1 (top left panel, red), or with mAb L8 (bottom left panel, green). Normal breast $(n=8)$ was stained for FVIIIRAg (top right panel, red), or with mAb L8 (bottom right panel, green). that regulate cell fate and function (McBeath et al. 2004; Discher et al. 2005; Engler et al. 2006; Larsen et al. 2006; Vogel and Sheetz 2006; Yamada and Cukierman 2007). Given a 3D-specific requirement for Fn matrix deposition in the assembly of organized cell-matrix adhesive sites, the ability of embedded endothelial cells to generate tractional forces on the fibrin matrix was determined in the presence or absence of Fn fibrillogenesis inhibitors. In stressed ECM gels wherein cells are permitted to exert isometric tension, the degree of force exerted by cells on the surrounding fibrillar network can be assessed by monitoring gel contraction after the matrix is released from the surrounding culture dish (Corbett and Schwarzbauer 1999; Even-Ram et al. 2007). As shown in
Figure 6, growth factor-stimulated endothelial cells cultured in control gels for $48 \mathrm{~h}$ were able to actively contract the released fibrin gel. In contrast, each of the Fn fibrillogenesis inhibitors markedly attenuated the ability of the embedded endothelial cells to generate tractional forces under 3D (Fig. 6A), but not 2D (data not shown), culture conditions.

Tractional forces exerted at cell-matrix adhesion sites require the activation of an actinomyosin motor complex whose assembly is tightly linked to actin cytoskeleton organization, nonmuscle myosin II isoform expression, and the rigidity of the surrounding substratum (Meshel et al. 2005; Engler et al. 2006; Even-Ram et al. 2007; Yoneda et al. 2007). Given that 
A

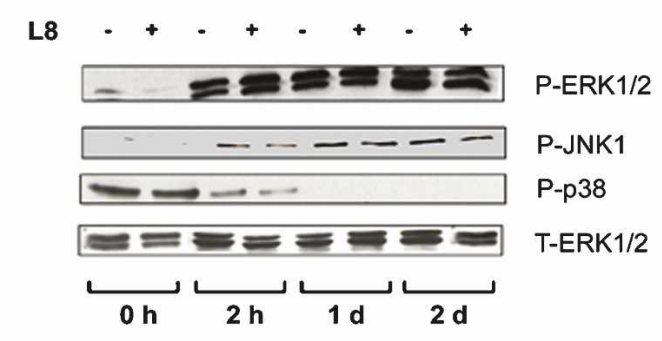

B

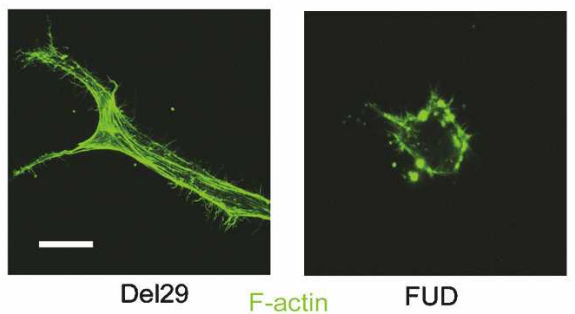

C
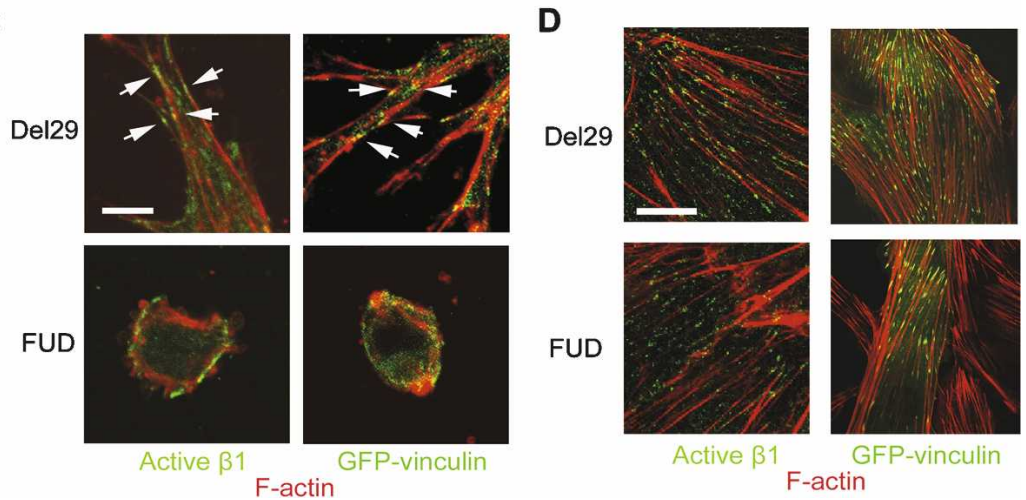

Figure 5. The 3D Fn matrix is required for endothelial cell cytoskeletal organization and adhesion. $(A)$ Levels of phosphorylated ERK1/2, JNK, and p38 were determined by immunoblot analysis in lysates of endothelial cells embedded in fibrin gels in the presence of either control IgG or mAb L8 for $0 \mathrm{~h}, 2 \mathrm{~h}, 1 \mathrm{~d}$, or $2 \mathrm{~d}$. Total ERK1/2 serves as the loading control. (B) Endothelial cells were cultured in $3 \mathrm{D}$ fibrin gels in the presence of the FUD or control peptides for $2 \mathrm{~d}$. F-actin cytoskeletal organization was monitored following staining with Alexa 488-conjugated phalloidin and confocal laser microscopy. Bar, $20 \mu \mathrm{m}$. (C) Endothelial cells in 3D fibrin matrices in the presence or absence of FUD were either stained with an antibody against activated $\beta_{1}$ integrin (green, left panels) or transfected with a GFP-tagged vinculin expression vector (pRK-vinculin-EGFP, green, right panels). Following counterstaining with Alexa 594labeled phalloidin (red), fluorescence was monitored by confocal laser microscopy. Bar, $10 \mu \mathrm{m} .(D)$ Endothelial cells were cultured atop a 2D fibrin gel for $2 \mathrm{~d}$ in the presence of either Del29 or FUD peptides. In tandem with staining with Alexa 594-labeled phalloidin to monitor cytoskeletal organization, actve $\beta_{1}$ integrin and vinculin distribution were monitored by staining with an antibody against active $\beta_{1}$ integrin (left panels) or assessing GFP-vinculin localization (right panels), respectively, by confocal microscopy. Bar, $20 \mu \mathrm{m}$.

Fn matrix rigidity or adhesivity can affect the expression of gene products critical to the generation of tractional forces (Ben-Ze'ev et al. 1980; Deroanne et al. 2001; Engler et al. 2006), we monitored $\beta$-actin, $\alpha$-actinin, myosin light chain-2 (MLC2), as well as nonmuscle myosin IIA and IIB isoforms (NMMIIA and NMMIIB, respectively) protein levels in 3D-embedded endothelial cells (Fig. 6B). Significantly, whereas each cytoskeletal component is expressed in growth factor-stimulated endothelial cells actively assembling a Fn matrix, endothelial cells cultured in the presence of FUD or L8 express markedly reduced levels of $\beta$-actin, $\alpha$-actinin, and MLC2 (Fig. 6B; Engler et al. 2006; Clark et al. 2007; Even-Ram et al. 2007).

\section{Sensing extracellular stiffness through Fn fibrillogenesis}

Endothelial cells cultured atop highly malleable surfaces retain a spheroid configuration, fail to organize stress fibers, and are unable to exert tractional forces (Folkman and Moscona 1978; Chen et al. 1997; Georges and Janmey 2005; Engler et al. 2006) - a phenotype identical to that observed in 3D-embedded, Fn matrix assembly-incompetent endothelial cells. As the cell's internal stiffness-a viscoelastic property governed by cytoskeletal assembly, actin cross-linking, and the production of actomyosin-dependent stress-changes as a function of the perceived stiffness of the surrounding substratum (Solon et al. 2007), intracellular nanorheology was used to 
Figure 6. Fn matrix assembly regulates the generation of 3D-specific myosin-dependent tension and intracellular rigidity. $(A)$ $3 \mathrm{D}$ fibrin gels were cast in individual wells of 24-well plates and cultured alone or in the presence of embedded endothelial cells for $2 \mathrm{~d}$ in the presence of control $\operatorname{IgG}, \mathrm{mAb}$ L8, mAb 9D2, the 70-kDa Fn fragment, or the FUD peptide. Gels were detached from the edges of the culture wells and contraction-monitored after an additional incubation period of $10 \mathrm{~h}$ at $37^{\circ} \mathrm{C}$. The percentage inhibition of gel contraction (measured as the change in gel diameter) relative to an IgG control is presented. Inset shows photographs (from left to right) of a cell-free fibrin gel, a gel contracted by embedded endothelial cells, and gels contracted by endothelial cells cultured in the presence of either $\mathrm{mAb} 9 \mathrm{D} 2$ or $\mathrm{mAb} \mathrm{L} 8$ or the $70-\mathrm{kDa}$ Fn fragment. $(B)$ Endothelial cells were cultured in $3 \mathrm{D}$ fibrin gels for $2 \mathrm{~d}$ with either the FUD peptide or the control Del29 peptide. Levels of $\beta$-actin, $\alpha$-actinin, NMMIIA, NMMIIB, and MLC2 were measured by Western blot, with ERK1/2 serving as the loading control. As assessed by semiquantitative densitometry, the levels of $\beta$-actin, actinin, and MLC2 were $58 \pm 7 \%(n=5 ;$ mean \pm 1 SD), $62 \% \quad(n=2)$, and $60 \pm 12 \% \quad(n=3$; mean \pm 1 SD) of control. (C) Prior to embedding in the $3 \mathrm{D}$ fibrin matrix, endothelial cells were ballistically microinjected with $100-\mathrm{nm}$ polystyrene beads. After 3-d incubation, the beads dispersed in the cytoplasm and their centroids were tracked with high spatial and temporal resolution using fluorescence microscopy. Bar, $10 \mu \mathrm{m}$. (D) Typical trajectories of beads in the cytoplasm of 3D-embedded cells, under control conditions (black, left panel) and in the presence of FUD (green, right panel). Time of movie capture, $20 \mathrm{sec}$. Bar, $50 \mathrm{~nm}$. (E) Ensembleaveraged MSDs of beads in the cytoplasm of 3D-embedded endothelial cells under con-
A

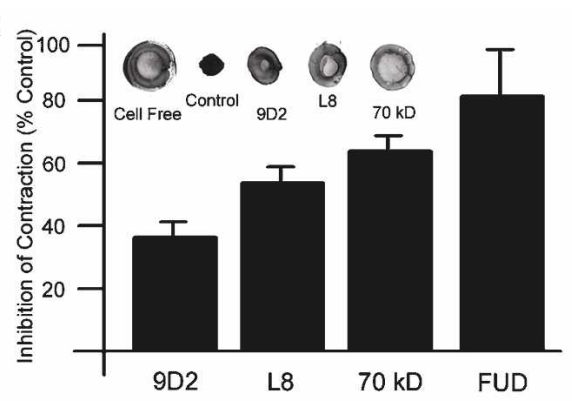

C

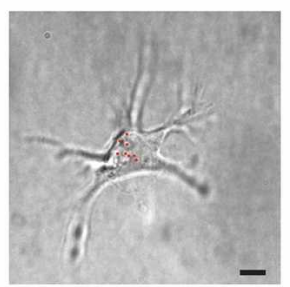

E

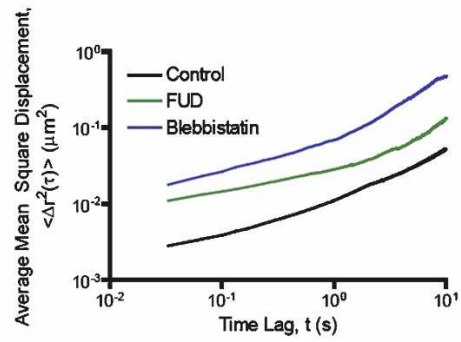

G

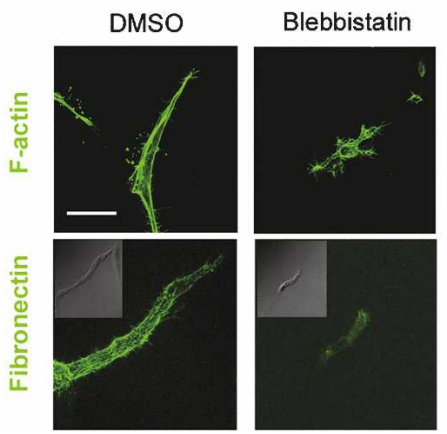

B

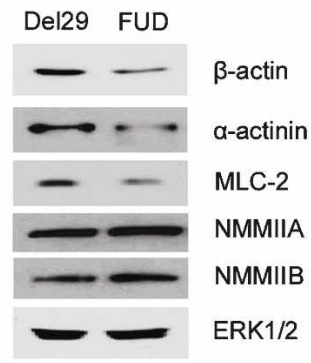

D

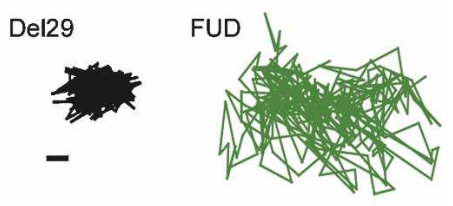

$\mathbf{F}$

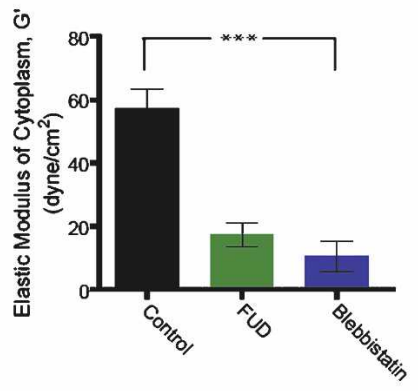

H

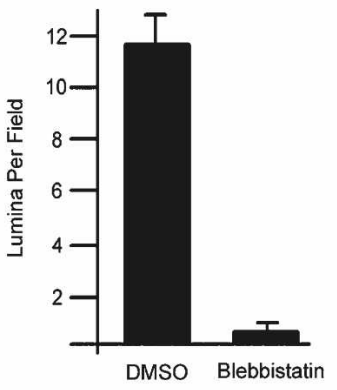

trol conditions (black curve) and in the presence of FUD (green curve) or blebbistatin (blue curve). MSDs were computed from displacements of the beads such as shown in $D$. At least 110 beads in at least 10 cells were tracked for each condition. $(F)$ Averaged elastic modulus of cells under control conditions or in the presence of FUD or blebbistatin. $\left(^{\star \star \star}\right) P<0.001$. $(G)$ Endothelial cells were cultured in 3D fibrin gels for $2 \mathrm{~d}$ in the presence or absence of $50 \mu \mathrm{M} \pm$ blebbistatin when F-actin organization and Fn matrix assembly were monitored by confocal laser microscopy. (Top panels) F-actin organization was monitored by staining with Alexa 488-conjugated phalloidin. (Bottom panels) Fn matrix assembly was assessed by culture in the presence of FITC-conjugated Fn. Bar, $20 \mu \mathrm{m}$. (H) Endothelial cells were cultured in 3D fibrin gels for $6 \mathrm{~d}$ under provasculogenic conditions in the presence of $50 \mu \mathrm{M} \pm$ blebbistatin or vehicle (DMSO). Tubulogenesis was monitored following sectioning, H\&E staining, and lumen quantification.

monitor the micromechanical properties of 3D-embedded endothelial cells. One-hundred-nanometer-diameter fluorescent polystyrene beads were ballistically injected into the endothelial cell cytoplasm before the cells were cultured within the $3 \mathrm{D}$ fibrin matrix to circumvent the endocytic pathway and subsequent directed motion of the beads (Tseng et al. 2002). After 72 h, beads dispersed uniformly in the cytoplasm (e.g., Fig. 6C), and their (random) displacements within the cytoplasm (Fig. 6D) were analyzed with the appropriate software (see details in
Materials and Methods). As shown in Figure 6E, relative to control endothelial cells, the mean square displacement (MSD) of the beads is significantly increased in cells treated with the FUD peptide, indicating a significant relative cytoplasmic softening compared with that of cells where Fn matrix assembly is intact. Elastic moduli $\left(G^{\prime}\right.$, expressed in dyne per square centimeter), which quantify the local resistance of the cytoplasm against small random forces acting on the surface of the beads, were derived from MSD curves to quantify cellu- 
lar mechanical properties. The elastic modulus of the cytoplasm of FUD-treated cells is significantly lower than that of control cells $(P<0.001)$, indicating a pronounced defect in internal stiffness and the cell's ability to sense a sufficiently rigid substratum (Fig. 6F).

In the absence of Fn fibrillogenesis, an impaired ability of embedded endothelial cells to generate myosin-dependent forces and increase cytoplasmic stiffness would be predicted to affect both Fn unfolding (Wu et al. 1995; Zhong et al. 1998; Baneyx et al. 2002; Yoneda et al. 2007) as well as the ability of the cells to properly register the mechanical properties of the surrounding substratum (Discher et al. 2005; Engler et al. 2006). As such, the rheological and functional characteristics of endothelial cells were assessed in the presence of the specific myosin ATPase inhibitor, blebbistatin (Engler et al. 2006; Clark et al. 2007). Blebbistatin-treated endothelial cells phenocopy Fn matrix assembly-incompetent cells and fail to increase cytoplasmic stiffness, undergo cell shape change, assemble a pericellular Fn matrix, or reorganize cytoskeletal architecture (Fig. 6E-G). Consequently, endothelial cell tubulogenesis is blocked completely (Fig. $6 \mathrm{H})$. Hence, myosin ATPase activity and Fn matrix assembly play required roles in regulating the endothelial cell's ability to match internal stiffness with that of the surrounding substratum so as to propagate the mechanotransduction-initiated signals critical to neovessel formation.

\section{Discussion}

By modulating the responsiveness of endothelial cells to soluble agonists, the biomechanical properties of the ECM play critical roles in regulating vasculogenesis and angiogenesis (Chen et al. 1997; Huang et al. 1998; Discher et al. 2005; Georges and Janmey 2005; Ingber 2006). Here, we demonstrate that endothelial cell function within the specific confines of the 3D ECM is unexpectedly regulated by Fn fibrillogenesis. Fn, a disulfide-linked dimer of subunits composed of three types of repeating modules (i.e., type I, II, and III repeats), binds to the endothelial cell surface by displaying a dominant cell-adhesive domain (module $\mathrm{III}_{9,10}$ ), a C-terminal heparin-binding domain (module $\mathrm{III}_{12-14}$ ), and a $70-\mathrm{kDa} \mathrm{N}$ terminal domain that are recognized by integrins, syndecans, and Fn matrix assembly sites, respectively (Mao and Schwarzbauer 2005; Tomasini-Johansson et al. 2006). Once the soluble Fn dimer engages adhesion molecules on the endothelial cell surface, signaling cascades are triggered that initiate the unfolding of the globular glycoprotein and the consequent exposure of cryptic domains, which then serve to support Fn polymerization and matrix assembly (Geiger et al. 2001; Mao and Schwarzbauer 2005; Tomasini-Johansson et al. 2006). As observed during both vasculogenesis and angiogenesis in vivo (Clark et al. 1982; Risau and Lemmon 1988; Kim et al. 2000; Francis et al. 2002; Hynes 2002; Neri and Bicknell 2005), endothelial cells embedded in 3D fibrin or collagen-rich gels rapidly assemble a pericellular Fn matrix following stimulation with proangiogenic growth factors. While $\alpha_{5} \beta_{1}-F n$ interactions have been established previously to regulate vascular development in vivo by heretofore undefined mechanisms, Fn monomers are known to initiate $\alpha_{5} \beta_{1}$-dependent signaling cascades that operate independently of the polymerization process per se (Geiger et al. 2001; Larsen et al. 2006). As such, a specific role for Fn fibrillogenesis in 3D neovessel formation has not been considered previously. Although earlier reports concluded that endothelial cell signaling in 2D culture is dependent on Fn matrix assembly (Bourdoulous et al. 1998), these studies employed a Fn-derived peptide as an inhibitory fragment that has since been shown to modulate cell function independently of effects on Fn fibrillogenesis (Ambesi et al. 2005). Indeed, our findings, as well as those of others (Mercurius and Morla 1998; Tomasini-Johansson et al. 2001), demonstrate that under $2 \mathrm{D}$ conditions, cell adhesion, migration, and proliferation proceed independently of Fn matrix assembly.

Optimal cell-matrix adhesive interactions induce the assembly of a cytoskeletal network that is required for the support of cell shape changes that, in turn, activate mechanotransduction-sensitive signaling cascades (Engler et al. 2004; Discher et al. 2005; Cai et al. 2006; Vogel and Sheetz 2006; Galbraith et al. 2007). If, however, endothelial cell shape changes are prevented under planar conditions (e.g., by altering ligand topology or decreasing matrix rigidity), the adherent cells are unable to rearrange their cytoskeletal architecture to exert tractional forces on the underlying substratum, and either senesce or undergo apoptosis (Folkman and Moscona 1978; Chen et al. 1997; Huang et al. 1998; Georges and Janmey 2005). In $3 \mathrm{D}$ culture, endothelial cell responses to proangiogenic agonists are similarly disengaged when pericellular Fn matrix assembly is blocked and the cells are unable to use the multiple ligands presented by dense matrices of fibrin or type I collagen as structural platforms in either the in vitro or in vivo settings. Recent studies demonstrate that cells "sense" the mechanical properties of the surrounding matrix via a myosin II-dependent pathway (Discher et al. 2005; Solon et al. 2007). Consequently, the adherent cells alter their intracellular stiffness to match that of the supporting ECM in order to initiate the appropriate acytomyosin-dependent responses (Discher et al. 2005; Engler et al. 2006; Solon et al. 2007). Given that (1) the 3D behavior of Fn fibrillogenesis-incompetent endothelial cells phenocopies that of cells cultured atop suboptimal substrata and (2) internal cellular stiffness is modulated as a function of the perceived stiffness of the extracellular substratum (Engler et al. 2006; Solon et al. 2007), we reasoned that $3 \mathrm{D}$ analyses of microrheological responsiveness might uncover a required role for Fn matrix assembly in allowing endothelial cells to discern the biomechanical characteristics of the pericellular environment. Embedded in a 3D matrix, cells are inaccessible to conventional physical probes, including atomic force microscopy, glass microneedles, membrane-bound magnetic beads, or micropipette suction (Tseng et al. 2002). Using intracellular nanorheology, however, the random movements of submicron particles microin- 
jected into the cytoplasm can be monitored as a means to determine local viscoelasticity (Tseng et al. 2002; Panorchan et al. 2007). Based on such analyses, we demonstrate that $3 \mathrm{D}$-embedded endothelial cells sense and respond to a sufficiently rigid scaffolding only when a network of Fn polymers is interposed between the cell and surrounding matrix of fibrin and/or type I collagen.

The ability of Fn matrix assembly to regulate endothelial cell mechanotransduction signaling is likely ascribed to either of two, not necessarily mutually exclusive, processes. First, as Fn fibrils are cross-linked into insoluble mats by both covalent and noncovalent interactions (Mao and Schwarzbauer 2005), the assembled matrix may increase local mechanical rigidity to a degree necessary to support the tractional forces and intracellular stiffening generated during cell spreading (Davidson et al. 2004). Indeed, in preliminary studies designed to directly monitor changes in the rigidity of the pericellular matrix, we found that endothelial cells modulate the local mechanical rigidity of the ECM by a process dependent on Fn fibrillogenesis (R.G. Rowe, J.B. George, D. Wirtz, and S.J. Weiss, unpubl.). Second, Fn matrix assembly allows for an increase in the local concentration and order of potential $\alpha_{5} \beta_{1}$ integrin-binding sites that would serve as a structural platform for cell spreading (Geiger et al. 2001; Mao and Schwarzbauer 2005). Unfolded Fn molecules could further alter cell function by displaying matricryptic heparin-binding sites (Gui et al. 2006). As neither mechanically soft matrices displaying high adhesivity nor rigid matrices decorated with suboptimal levels of proadhesive binding sites will induce changes in cytoskeletal architecture and intracellular stiffness (Discher et al. 2005; Solon et al. 2007), endothelial cells apparently use Fn matrix assembly to purposefully deposit an elastic layer of proadhesive binding sites whose concentration and topology support neovessel formation.

In vivo, Fn is expressed transiently around the developing vasculature during both vasculogenesis and angiogenesis (Clark et al. 1982; Risau and Lemmon 1988; Neri and Bicknell 2005). As the vasculature matures, Fn expression wanes, and the maturing blood vessels are invested with a type IV collagen/laminin-rich basement membrane (Risau and Lemmon 1988; Jain 2003). Fn is re-expressed, however, in the neovasculature surrounding wound sites or tumors (Neri and Bicknell 2005). Significantly, large deposits of unfolded Fn could be detected in association with neovessels infiltrating cancerous tissues. While Fn fibrils are also found, as expected, in association with fibroblasts, it is important to stress that we were unable to identify a similarly critical role for Fn matrix assembly in fibroblast function-under either 2D or 3D culture conditions (Supplemental Fig. 3). These findings reinforce earlier reports where inhibitors of Fn fibrillogenesis did not affect fibroblast behavior in 3D collagen gels (Halliday and Tomasek 1995). Similar analyses of Fn matrix assembly in wild-type and Fn knockout embryos indicate that distinct differences exist between embryonic fibroblast and endothelial cell behavior in vivo and in vitro (George et al. 1993; Deroanne et al. 1996; Hocking et al. 2000; Sottile et al. 2000; Dero- anne et al. 2001; Francis et al. 2002). Cell type-specific responses to Fn fibrillogenesis are likewise consistent with more recent findings that mesenchymal cell populations display singular mechanical requirements for optimizing their responses to matrix-derived signals (McBeath et al. 2004; Georges and Janmey 2005; Engler et al. 2006). Interestingly, a unique role for Fn in the specific regulation of endothelial cell behavior is supported by the fact that unlike most ECM molecules, Fn expression is limited to vertebrates, and its appearance in evolution coincides with the appearance of the vasculature (Hynes and Zhao 2000).

With increasing frequency, the morphology, adhesive interactions, and behavior of cells are recognized as being uniquely affected by the dimensionality of their surrounding matrix environment (Hotary et al. 2003; Debnath and Brugge 2005; Chun et al. 2006; Nelson and Bissell 2006; Yamada and Cukierman 2007). Under 3D conditions, we posit that the random intertwining of the surrounding fibrin or collagen fibrils precludes the highdensity, planar display of adhesive ligands on a rigid template that can support integrin clustering and/or cellular traction. These data are consistent with a model wherein the endothelial cell has elected to assemble its own pericellular matrix of polymerized Fn to meet the spatial and structural constraints placed on transmitting extracellular signals to intracellular compartments and effectors. By regulating cell shape, stiffness sensing, and mechanotransduction, Fn matrix assembly is shown to serve as a multifaceted and 3D-specific regulator of neovessel formation that may prove useful as a target for therapeutic intervention in pathologic states.

\section{Materials and methods}

\section{Endothelial cell isolation and 2D/3D culture}

Endothelial cells were isolated from human umbilical cord veins by collagenase digestion and cultured in Medium 199 (Gibco) containing $20 \%$ human serum, $50 \mu \mathrm{g} / \mathrm{mL}$ endothelial cell growth supplement (BD Biosciences), $100 \mathrm{U} / \mathrm{mL}$ penicillin, and $100 \mu \mathrm{g} / \mathrm{mL}$ streptomycin (Hiraoka et al. 1998). For 2D/3D culture, endothelial cell monolayers (no later than third passage) were suspended by mild trypsinization and dispersed within or plated atop fibrin $(3 \mathrm{mg} / \mathrm{mL})$ or collagen $(2.2 \mathrm{mg} / \mathrm{mL})$ gels (prepared as described; Hiraoka et al. 1998; Hotary et al. 2003), and stimulated with a cocktail of growth factors including $100 \mathrm{ng} / \mathrm{mL}$ human vascular endothelial growth factor (VEGF) (Genentech), $50 \mathrm{ng} / \mathrm{mL}$ human hepatocyte growth factor (HGF) (Genentech), $10 \mathrm{ng} / \mathrm{mL}$ human TGF $\alpha$ (Biosource), $0.5 \mathrm{ng} /$ $\mathrm{mL}$ TGF $\beta_{1}$ (R\&D Systems), and $100 \mu \mathrm{g} / \mathrm{mL}$ heparin (Sigma). In selected experiments, endothelial cell spheroids were prepared and suspended in $3 \mathrm{D}$ fibrin gels.

To monitor Fn matrix assembly or to assess the impact of inhibiting Fn matrix assembly on endothelial cell function, human serum was depleted of Fn by gelatin-sepharose affinity chromatography (Amersham) and supplemented with either 20 $\mu \mathrm{g} / \mathrm{mL}$ human plasma Fn (Sigma) or fluorescein isothiocyanate (FITC)-labeled Fn. Where indicated, endothelial cells were incubated with mouse IgG (Pierce), monoclonal antibody L8, monoclonal antibody 9D2 (final concentration of $100 \mu \mathrm{g} / \mathrm{mL}$ ), the $70-\mathrm{kDa}$ Fn fragment $(75 \mu \mathrm{g} / \mathrm{mL}$; Sigma), the FUD peptide 
(250 nM), \pm blebbistatin ( $50 \mu \mathrm{M}$; Calbiochem), or cytochalasin D (10 $\mathrm{MM}$; Sigma) during 3D culture. Cell number in 3D cultures was determined by hemacytometry after dissolving gels with 2 $\mathrm{mg} / \mathrm{mL}$ bacterial collagenase (Worthington) while the number of patent tubules was determined in randomly selected crosssections.

To monitor endothelial cell contractility, 2D or 3D cultures cast in 24-well plates at $2 \mathrm{~d}$ incubation (prior to commencement of $3 \mathrm{D}$ proliferation) were detached from the tissue culture plate and cells were allowed to contract the matrices for $10 \mathrm{~h}$, at which time gel diameter was measured. To assess migration in $2 \mathrm{D}$, endothelial cells were plated atop a fibrin substratum in the presence of a glass coverslip. After attachment, the coverslip was removed and migration into the cell-free area monitored over $2 \mathrm{~d}$. To monitor 3D migration, endothelial cells were suspended in 3D fibrin gels in 96-well tissue culture plates. After formation of the fibrin gel, the gels were removed and embedded within fibrin gels in 24-well plates. Migration from the inner gel into the outer gel was monitored over $6 \mathrm{~d}$.

\section{Antibody purification and fluorescent Fn labeling}

9D2 monoclonal antibody was purified from the 9D2 hybridoma cell line (Sottile et al. 1998) by Staph protein A/G affinity chromatography following the manufacturer's protocol (Pierce). The L8 monoclonal was purified as described previously (Chernousov et al. 1991). Human plasma Fn (Sigma) was labeled with FITC as described (McKeown-Longo and Mosher 1985).

\section{Western blot and immunofluorescence}

For Western blotting, the following antibodies were used: ERK1/2 (Santa Cruz Biotechnology), phospho-p42/44 MAPK (Thr202/Tyr204), phospho-p38 MAPK (Thr180/Tyr182), $\beta$-actin, $\alpha$-actinin (Cell Signaling Technologies), NMMIIA, and NMMIIB (Covance). Phosphorylated JNK was detected following pull-down with c-Jun fusion protein beads (Cell Signaling Technologies) and probed with phospho-SAPK/JNK1/2 (Thr183/ Tyr185) polyclonal antibody (Cell Signaling Technologies).

For active $\beta_{1}$ integrin immunofluorescence, 3D cultures were fixed in $4 \%$ formaldehyde, permeabilized with $0.25 \%$ Triton $\mathrm{X}-100$, and incubated overnight with an anti-active $\beta_{1}$ monoclonal antibody (Chemicon) followed by an Alexa 488-conjugated secondary antibody (Molecular Probes). For visualization of the F-actin cytoskeleton, cultures were stained with Alexa 594- or Alexa 488-conjugated phalloidin (Molecular Probes) following permeabilization. To examine the 3D Fn matrix, fibrin gels supplemented with $20 \mu \mathrm{g} / \mathrm{mL}$ FITC-labeled Fn were fixed with $4 \%$ formaldehyde. All 3D gels were analyzed by confocal microscopy.

\section{Histology and transmission electron microscopy (TEM)}

$3 \mathrm{D}$ cultures were fixed in $4 \%$ formaldehyde, processed for paraffin-embedded sectioning and standard haematoxylin and eo$\sin (\mathrm{H} \& \mathrm{E})$ staining. TEM was carried out as described previously (Hiraoka et al. 1998; Hotary et al. 2003).

\section{Plasmid constructs and transfection}

The pRK/EGFP-vinculin vector was introduced into endothelial cells by lipofectamine-mediated transfection (Invitrogen). Cells were used for $3 \mathrm{D}$ culture $24 \mathrm{~h}$ following transfection.

\section{Chorioallantoic membrane angiogenesis assay}

$3 \mathrm{D}$ matrices of type I collagen or a type I collagen/fibrin composite matrix were cast in transwell tissue culture inserts (24- well size) perforated with a 25-gauge needle. A $30-\mu \mathrm{L}$ Matrigel (BD Biosciences) reservoir was placed atop the matrix containing $200 \mathrm{ng}$ of VEGF, $100 \mathrm{ng}$ of HGF, and either the del29 or FUD peptides. The entire apparatus was placed atop the dropped CAM of 10- to 11-d-old fertile chicken eggs. Following incubation in a humidified incubator for $3 \mathrm{~d}$ at $37^{\circ} \mathrm{C}$, the matrices were harvested and processed for sectioning and $H \& E$ staining.

\section{$3 D$ intracellular microrheology}

The micromechanical properties of the cytoplasm of endothelial cells embedded in the 3D were measured using the method of ballistic intracellular nanorheology (Panorchan et al. 2006, 2007). To our knowledge, this is the only method capable of probing the intracellular micromechanics of single cells embedded in a 3D matrix. Briefly, 100-nm-diameter polystyrene fluorescent beads were ballistically injected in the cytoplasm of cells using a biolistic particle delivery system (Bio-Rad) (Lee et al. 2006). The cells were then incorporated in the $3 \mathrm{D}$ fibrin matrix. After $72 \mathrm{~h}$ of incubation, the beads (between five and 10 per cell) had dispersed uniformly in the cytoplasm and their centroids were tracked for $20 \mathrm{sec}$ with high spatial $(\sim 5 \mathrm{~nm})$ and temporal (33 msec) resolutions using a Cascade $1 \mathrm{k}$ CCD camera (Roper Scientific) mounted on a Nikon Eclipse TE2000-E epifluorescence microscope and controlled by the software Metaview (Universal Imaging). The MSDs of individual beads were computed from the time-dependent $(\mathrm{x}, \mathrm{y})$ coordinates of the beads' centroid displacements. The MSDs were verified to have a slope $<1$; i.e., no directed motion of the beads was ever observed. A simple mathematical manipulation detailed in Tseng et al. (2002) was used to transform MSDs into elastic modulus (reported here) and viscous modulus of the cytoplasm. The number of individual cells and total number of beads tracked for each type of cell are indicated in the legend for Figure 6. Mean values, standard error of measurement (SEM), and statistical analysis of bead displacements were calculated and plotted using Graphpad Prism (Graphpad Software). Two-tailed unpaired $t$-tests were conducted to determine significance, which was indicated using the standard Michelin Guide scale.

\section{Acknowledgments}

We thank M. Ensenberger (University of Wisconsin-Madison) for the production and characterization of the Del29 control peptide, S. Lin (University of California at Irvine) for GFP-vinculin, and J. Sottile (University of Rochester) for 9D2. This work was supported by the National Institutes of Health (CA88308 to S.J.W. and HL21644 to D.F.M.), and a graduate training grant of the Howard Hughes Medical Institute (R21 EB006890 to D.W.).

\section{References}

Ambesi, A., Klein, R.M., Pumiglia, K.M., and McKeown-Longo, P.J. 2005. Anastellin, a fragment of the first type III repeat of fibronectin, inhibits extracellular signal-regulated kinase and causes G(1) arrest in human microvessel endothelial cells. Cancer Res. 65: 148-156.

Baneyx, G., Baugh, L., and Vogel, V. 2002. Fibronectin extension and unfolding within cell matrix fibrils controlled by cytoskeletal tension. Proc. Natl. Acad. Sci. 99: 5139-5143.

Beningo, K.A., Dembo, M., and Wang, Y.L. 2004. Responses of fibroblasts to anchorage of dorsal extracellular matrix receptors. Proc. Natl. Acad. Sci. 101: 18024-18029.

Ben-Ze'ev, A., Farmer, S.R., and Penman, S. 1980. Protein synthesis requires cell-surface contact while nuclear events re- 
spond to cell shape in anchorage-dependent fibroblasts. Cell 21: $365-372$.

Bershadsky, A., Kozlov, M., and Geiger, B. 2006. Adhesion-mediated mechanosensitivity: A time to experiment, and a time to theorize. Curr. Opin. Cell Biol. 18: 472-481.

Bourdoulous, S., Orend, G., MacKenna, D.A., Pasqualini, R., and Ruoslahti, E. 1998. Fibronectin matrix regulates activation of RHO and CDC42 GTPases and cell cycle progression. J. Cell Biol. 143: 267-276.

Cai, Y., Biais, N., Giannone, G., Tanase, M., Jiang, G., Hofman, J.M., Wiggins, C.H., Silberzan, P., Buguin, A., Ladoux, B., et al. 2006. Nonmuscle myosin IIA-dependent force inhibits cell spreading and drives F-actin flow. Biophys. J. 91: 39073920.

Carmeliet, P. 2005. Angiogenesis in life, disease and medicine. Nature 438: 932-936.

Cavalcanti-Adam, E.A., Volberg, T., Micoulet, A., Kessler, H., Geiger, B., and Spatz, J.P. 2007. Cell spreading and focal adhesion dynamics are regulated by spacing of integrin ligands. Biophys. I. 92: 2964-2974.

Chen, C.S., Mrksich, M., Huang, S., Whitesides, G.M., and Ingber, D.E. 1997. Geometric control of cell life and death. Science 276: 1425-1428.

Chernousov, M.A., Fogerty, F.J., Koteliansky, V.E., and Mosher, D.F. 1991. Role of the I-9 and III-1 modules of fibronectin in formation of an extracellular fibronectin matrix. I. Biol. Chem. 266: 10851-10858.

Christopher, R.A., Kowalczyk, A.P., and McKeown-Longo, P.J. 1997. Localization of fibronectin matrix assembly sites on fibroblasts and endothelial cells. I. Cell Sci. 110: 569-581.

Chun, T.H., Sabeh, F., Ota, I., Murphy, H., McDonagh, K.T., Holmbeck, K., Birkedal-Hansen, H., Allen, E.D., and Weiss, S.J. 2004. MT1-MMP-dependent neovessel formation within the confines of the three-dimensional extracellular matrix. J. Cell Biol. 167: 757-767.

Chun, T.H., Hotary, K.B., Sabeh, F., Saltiel, A.R., Allen, E.D., and Weiss, S.J. 2006. A pericellular collagenase directs the 3-dimensional development of white adipose tissue. Cell 125: 577-591.

Clark, R.A., Quinn, J.H., Winn, H.J., Lanigan, J.M., Dellepella, P., and Colvin, R.B. 1982. Fibronectin is produced by blood vessels in response to injury. J. Exp. Med. 156: 646-651.

Clark, K., Langeslag, M., Figdor, C.G., and van Leeuwen, F.N. 2007. Myosin II and mechanotransduction: A balancing act. Trends Cell Biol. 17: 178-186.

Corbett, S.A. and Schwarzbauer, J.E. 1999. Requirements for $\alpha(5) \beta(1)$ integrin-mediated retraction of fibronectin-fibrin matrices. I. Biol. Chem. 274: 20943-20948.

Corson, L.B., Yamanaka, Y., Lai, K.M., and Rossant, J. 2003 Spatial and temporal patterns of ERK signaling during mouse embryogenesis. Development 130: 4527-4537.

Davidson, L.A., Keller, R., and DeSimone, D.W. 2004. Assembly and remodeling of the fibrillar fibronectin extracellular matrix during gastrulation and neurulation in Xenopus laevis. Dev. Dyn. 231: 888-895.

Debnath, J. and Brugge, J.S. 2005. Modelling glandular epithelial cancers in three-dimensional cultures. Nat. Rev. Cancer 5: $675-688$.

Deroanne, C.F., Colige, A.C., Nusgens, B.V., and Lapiere, C.M. 1996. Modulation of expression and assembly of vinculin during in vitro fibrillar collagen-induced angiogenesis and its reversal. Exp. Cell Res. 224: 215-223.

Deroanne, C.F., Lapiere, C.M., and Nusgens, B.V. 2001. In vitro tubulogenesis of endothelial cells by relaxation of the coupling extracellular matrix-cytoskeleton. Cardiovasc. Res. 49: $647-658$
Discher, D.E., Janmey, P., and Wang, Y.L. 2005. Tissue cells feel and respond to the stiffness of their substrate. Science 310: 1139-1143.

Eliceiri, B.P., Klemke, R., Stromblad, S., and Cheresh, D.A. 1998. Integrin $\alpha \mathrm{v} \beta 3$ requirement for sustained mitogen-activated protein kinase activity during angiogenesis. J. Cell Biol. 140: 1255-1263.

Engler, A., Bacakova, L., Newman, C., Hategan, A., Griffin, M., and Discher, D. 2004. Substrate compliance versus ligand density in cell on gel responses. Biophys. J. 86: 617-628.

Engler, A.J., Sen, S., Sweeney, H.L., and Discher, D.E. 2006. Matrix elasticity directs stem cell lineage specification. Cell 126: 677-689.

Even-Ram, S., Doyle, A.D., Conti, M.A., Matsumoto, K., Adelstein, R.S., and Yamada, K.M. 2007. Myosin IIA regulates cell motility and actomyosin-microtubule crosstalk. Nat. Cell Biol. 9: 299-309.

Folkman, J. and Moscona, A. 1978. Role of cell shape in growth control. Nature 273: 345-349.

Francis, S.E., Goh, K.L., Hodivala-Dilke, K., Bader, B.L., Stark, M., Davidson, D., and Hynes, R.O. 2002. Central roles of $\alpha 5 \beta 1$ integrin and fibronectin in vascular development in mouse embryos and embryoid bodies. Arterioscler. Thromb. Vasc. Biol. 22: 927-933.

Galbraith, C.G., Yamada, K.M., and Galbraith, J.A. 2007. Polymerizing actin fibers position integrins primed to probe for adhesion sites. Science 315: 992-995.

Geiger, B., Bershadsky, A., Pankov, R., and Yamada, K.M. 2001. Transmembrane crosstalk between the extracellular matrixcytoskeleton crosstalk. Nat. Rev. Mol. Cell Biol. 2: 793-805.

George, E.L., Georges-Labouesse, E.N., Patel-King, R.S., Rayburn, H., and Hynes, R.O. 1993. Defects in mesoderm, neural tube and vascular development in mouse embryos lacking fibronectin. Development 119: 1079-1091.

Georges, P.C. and Janmey, P.A. 2005. Cell type-specific response to growth on soft materials. I. Appl. Physiol. 98: $1547-1553$.

Gui, L., Wojciechowski, K., Gildner, C.D., Nedelkovska, H., and Hocking, D.C. 2006. Identification of the heparin-binding determinants within fibronectin repeat IIII: Role in cell spreading and growth. J. Biol. Chem. 281: 34816-34825.

Halliday, N.L. and Tomasek, J.J. 1995. Mechanical properties of the extracellular matrix influence fibronectin fibril assembly in vitro. Exp. Cell Res. 217: 109-117.

Hiraoka, N., Allen, E., Apel, I.J., Gyetko, M.R., and Weiss, S.J. 1998. Matrix metalloproteinases regulate neovascularization by acting as pericellular fibrinolysins. Cell 95: 365-377.

Hoang, M.V., Whelan, M.C., and Senger, D.R. 2004. Rho activity critically and selectively regulates endothelial cell organization during angiogenesis. Proc. Natl. Acad. Sci. 101: 1874-1879.

Hocking, D.C., Sottile, J., and Langenbach, K.J. 2000. Stimulation of integrin-mediated cell contractility by fibronectin polymerization. J. Biol. Chem. 275: 10673-10682.

Hotary, K.B., Allen, E.D., Brooks, P.C., Datta, N.S., Long, M.W., and Weiss, S.J. 2003. Membrane type I matrix metalloproteinase usurps tumor growth control imposed by the threedimensional extracellular matrix. Cell 114: 33-45.

Huang, S., Chen, C.S., and Ingber, D.E. 1998. Control of cyclin D1, p27(Kip1), and cell cycle progression in human capillary endothelial cells by cell shape and cytoskeletal tension. Mol. Biol. Cell 9: 3179-3193.

Hynes, R.O. 2002. A reevaluation of integrins as regulators of angiogenesis. Nat. Med. 8: 918-921.

Hynes, R.O. and Zhao, Q. 2000. The evolution of cell adhesion. J. Cell Biol. 150: F89-F96. doi: 10.1083/jcb.150.2.F89. 
Ingber, D.E. 2006. Cellular mechanotransduction: Putting all the pieces together again. FASEB J. 20: 811-827.

Jain, R.K. 2003. Molecular regulation of vessel maturation. Nat. Med. 9: 685-693.

Kim, S., Bell, K., Mousa, S.A., and Varner, J.A. 2000. Regulation of angiogenesis in vivo by ligation of integrin $\alpha 5 \beta 1$ with the central cell-binding domain of fibronectin. Am. I. Pathol. 156: $1345-1362$.

Korff, T. and Augustin, H.G. 1998. Integration of endothelial cells in multicellular spheroids prevents apoptosis and induces differentiation. J. Cell Biol. 143: 1341-1352.

Larsen, M., Artym, V.V., Green, J.A., and Yamada, K.M. 2006. The matrix reorganized: Extracellular matrix remodeling and integrin signaling. Curr. Opin. Cell Biol. 18: 463-471.

Lee, J.S., Panorchan, P., Hale, C.M., Khatau, S.B., Kole, T.P., Tseng, Y., and Wirtz, D. 2006. Ballistic intracellular nanorheology reveals ROCK-hard cytoplasmic stiffening response to fluid flow. J. Cell Sci. 119: 1760-1768.

Mao, Y. and Schwarzbauer, J.E. 2005. Fibronectin fibrillogenesis, a cell-mediated matrix assembly process. Matrix Biol. 24: 389-399.

McBeath, R., Pirone, D.M., Nelson, C.M., Bhadriraju, K., and Chen, C.S. 2004. Cell shape, cytoskeletal tension, and RhoA regulate stem cell lineage commitment. Dev. Cell 6: 483495.

McKeown-Longo, P.J. and Mosher, D.F. 1985. Interaction of the 70,000-mol-wt amino-terminal fragment of fibronectin with the matrix-assembly receptor of fibroblasts. J. Cell Biol. 100: 364-374.

Mercurius, K.O. and Morla, A.O. 1998. Inhibition of vascular smooth muscle cell growth by inhibition of fibronectin matrix assembly. Circ. Res. 82: 548-556.

Meshel, A.S., Wei, Q., Adelstein, R.S., and Sheetz, M.P. 2005. Basic mechanism of three-dimensional collagen fibre transport by fibroblasts. Nat. Cell Biol. 7: 157-164.

Nelson, C.M. and Bissell, M.J. 2006. Of extracellular matrix, scaffolds, and signaling: Tissue architecture regulates development, homeostasis, and cancer. Annu. Rev. Cell Dev. Biol. 22: 287-309.

Neri, D. and Bicknell, R. 2005. Tumour vascular targeting. Nat. Rev. Cancer 5: 436-446.

Panorchan, P., Lee, J.S., Kole, T.P., Tseng, Y., and Wirtz, D. 2006. Microrheology and ROCK signaling of human endothelial cells embedded in a 3D matrix. Biophys. I. 91: 34993507.

Panorchan, P., Lee, J.S.H., Daniels, B.R., Kole, T.P., Tseng, Y., and Wirtz, D. 2007. Probing cellular mechanical responses to stimuli using ballistic intracellular nanorheology. Methods Cell Biol. 83: 115-140.

Risau, W. and Lemmon, V. 1988. Changes in the vascular extracellular matrix during embryonic vasculogenesis and angiogenesis. Dev. Biol. 125: 441-450.

Solon, J., Levental, I., Sengupta, K., Georges, P.C., and Janmey, P.A. 2007. Fibroblast adaptation and stiffness matching to soft elastic substrates. Biophys. J. 93: 4453-4461.

Sottile, J., Hocking, D.C., and Swiatek, P.J. 1998. Fibronectin matrix assembly enhances adhesion-dependent cell growth. J. Cell Sci. 111: 2933-2943.

Sottile, J., Hocking, D.C., and Langenbach, K.J. 2000. Fibronectin polymerization stimulates cell growth by RGD-dependent and -independent mechanisms. J. Cell Sci. 113: 42874299.

Takahashi, S., Leiss, M., Moser, M., Ohashi, T., Kitao, T., Heckmann, D., Pfeifer, A., Kessler, H., Takagi, J., Erickson, H.P., et al. 2007. The RGD motif in fibronectin is essential for development but dispensable for fibril assembly. J. Cell Biol.
178: $167-178$.

Tan, J.L., Tien, J., Pirone, D.M., Gray, D.S., Bhadriraju, K., and Chen, C.S. 2003. Cells lying on a bed of microneedles: An approach to isolate mechanical force. Proc. Natl. Acad. Sci. 100: $1484-1489$.

Tomasini-Johansson, B.R., Kaufman, N.R., Ensenberger, M.G., Ozeri, V., Hanski, E., and Mosher, D.F. 2001. A 49-residue peptide from adhesin F1 of Streptococcus pyogenes inhibits fibronectin matrix assembly. J. Biol. Chem. 276: 23430-23439.

Tomasini-Johansson, B.R., Annis, D.S., and Mosher, D.F. 2006. The N-terminal $70-\mathrm{kDa}$ fragment of fibronectin binds to cell surface fibronectin assembly sites in the absence of intact fibronectin. Matrix Biol. 25: 282-293.

Tseng, Y., Kole, T.P., and Wirtz, D. 2002. Micromechanical mapping of live cells by multiple-particle-tracking microrheology. Biophys. J. 83: 3162-3176.

Velling, T., Risteli, J., Wennerberg, K., Mosher, D.F., and Johansson, S. 2002. Polymerization of type I and III collagens is dependent on fibronectin and enhanced by integrins $\alpha 11 \beta 1$ and $\alpha 2 \beta 1$. J. Biol. Chem. 277: 37377-37381.

Vogel, V. and Sheetz, M. 2006. Local force and geometry sensing regulate cell functions. Nat. Rev. Mol. Cell Biol. 7: 265-275.

Walpita, D. and Hay, E. 2002. Studying actin-dependent processes in tissue culture. Nat. Rev. Mol. Cell Biol. 3: 137-141.

Wu, C., Keivens, V.M., O'Toole, T.E., McDonald, J.A., and Ginsberg, M.H. 1995. Integrin activation and cytoskeletal interaction are essential for the assembly of a fibronectin matrix. Cell 83: 715-724.

Yamada, K.M. and Cukierman, E. 2007. Modeling tissue morphogenesis and cancer in 3D. Cell 130: 601-610.

Yoneda, A., Ushakov, D., Multhaupt, H.A., and Couchman, J.R. 2007. Fibronectin matrix assembly requires distinct contributions from Rho kinases I and II. Mol. Biol. Cell 18: 66-75.

Zhong, C., Chrzanowska-Wodnicka, M., Brown, J., Shaub, A., Belkin, A.M., and Burridge, K. 1998. Rho-mediated contractility exposes a cryptic site in fibronectin and induces fibronectin matrix assembly. J. Cell Biol. 141: 539-551. 


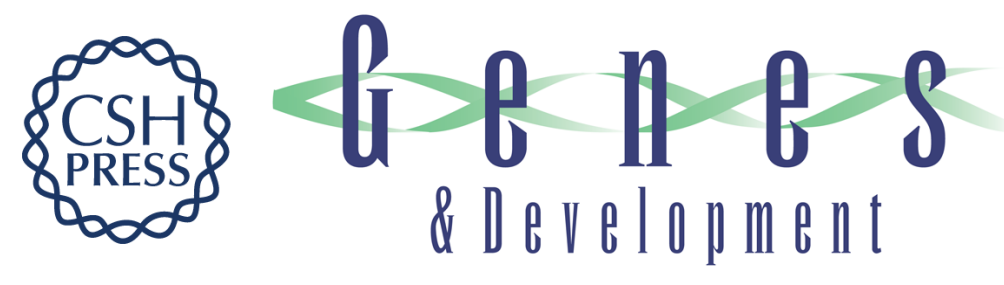

\section{Fibronectin fibrillogenesis regulates three-dimensional neovessel formation}

Xiaoming Zhou, R. Grant Rowe, Nobuaki Hiraoka, et al.

Genes Dev. 2008, 22:

Access the most recent version at doi:10.1101/gad.1643308

Supplemental http://genesdev.cshlp.org/content/suppl/2008/04/14/22.9.1231.DC1
Material

References This article cites 73 articles, 33 of which can be accessed free at:

http://genesdev.cshlp.org/content/22/9/1231.full.html\#ref-list-1

License

Email Alerting Receive free email alerts when new articles cite this article - sign up in the box at the top

Service right corner of the article or click here.

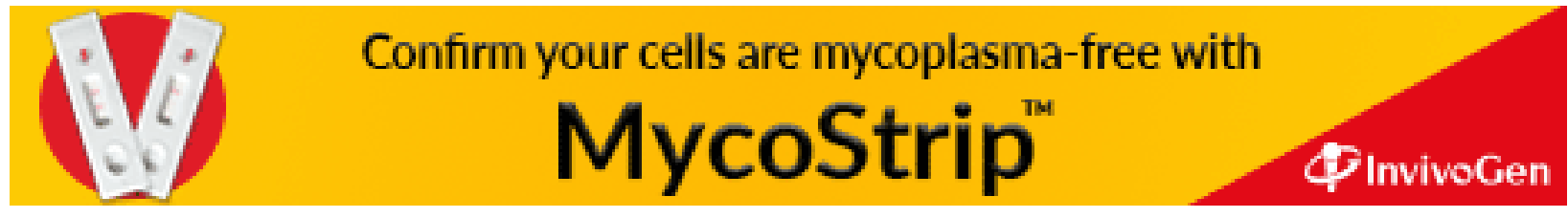

